\title{
Atypical Rett syndrome
}

INSERM

\section{Source}

INSERM. (1999). Orphanet: an online rare disease and orphan drug data base. Atypical

Rett syndrome. ORPHA:3095

Atypical Rett syndrome (atypical RTT) is a neurodevelopmental disorder that is diagnosed when a child presents with a Rett-like syndrome but does not fulfill all the diagnostic criteria for typical Rett syndrome (classic/typical RTT; see this term). 